\title{
Neuroendoscopic Resection of Intraventricular Tumors: A Systematic Outcomes Analysis
}

\author{
Sean M. Barber, Leonardo Rangel-Castilla, and David Baskin \\ Houston Methodist Neurological Institute, Department of Neurological Surgery, Suite 944, 6560 Fannin Street, Houston, \\ TX 77030, USA \\ Correspondence should be addressed to Sean M. Barber; smbarber@tmhs.org
}

Received 4 February 2013; Revised 8 July 2013; Accepted 8 August 2013

Academic Editor: Joachim Oertel

Copyright (c) 2013 Sean M. Barber et al. This is an open access article distributed under the Creative Commons Attribution License, which permits unrestricted use, distribution, and reproduction in any medium, provided the original work is properly cited.

Introduction. Though traditional microsurgical techniques are the gold standard for intraventricular tumor resection, the morbidity and invasiveness of microsurgical approaches to the ventricular system have galvanized interest in neuroendoscopic resection. We present a systematic review of the literature to provide a better understanding of the virtues and limitations of endoscopic tumor resection. Materials and Methods. 40 articles describing 668 endoscopic tumor resections were selected from the Pubmed database and reviewed. Results. Complete or near-complete resection was achieved in $75.0 \%$ of the patients. $9.9 \%$ of resected tumors recurred during the follow-up period, and procedure-related complications occurred in $20.8 \%$ of the procedures. Tumor size $\leq 2 \mathrm{~cm}$ $(P=0.00146)$, the presence of a cystic tumor component $(P<0.0001)$, and the use of navigation or stereotactic tools during the procedure $(P=0.0003)$ were each independently associated with a greater likelihood of complete or near-complete tumor resection. Additionally, the complication rate was significantly higher for noncystic masses than for cystic ones $(P<0.0001)$. Discussion. Neuroendoscopic outcomes for intraventricular tumor resection are significantly better when performed on small, cystic tumors and when neural navigation or stereotaxy is used. Conclusion. Neuroendoscopic resection appears to be a safe and reliable treatment option for patients with intraventricular tumors of a particular morphology.

\section{Introduction}

Intraventricular tumors present a unique challenge for the neurosurgeon. Their deep location and proximity to eloquent neurovascular anatomy complicate surgical approach and resection [1]. Microsurgery remains the gold standard for the treatment of intraventricular tumors [1-4], but microsurgical approaches are not without limitations [5-12]. The desire for a less invasive but equally effective surgical approach to intraventricular pathology has directed the attention of many in the neurosurgical community towards neuroendoscopy.

Neuroendoscopy was introduced in the early 1900s, adopted initially by Dandy [13] and others [14, 15] as a novel means of treating hydrocephalus [16], but the technique was overshadowed midcentury by the advent of the valved ventriculoperitoneal (VP) shunt $[17,18]$. Years later, neuroendoscopy regained popularity due to improvements in optical technology and the introduction of the rigid and flexible neuroendoscopes $[16,19,20]$. Today, neuroendoscopic techniques have further evolved, and the spectrum of intracranial pathologies treatable by modern neuro-endoscopic means continues to expand.

Early reports have demonstrated endoscopic resection of intraventricular masses to be effective and safe [21, 22]. The large majority of data in the neurosurgical literature, however, originate from studies of endoscopic colloid cyst resection $[11,23,24]$. Data regarding endoscopic resection of other intraventricular tumors exist primarily in case reports and small series with insufficient sample size to draw meaningful conclusions.

The goal of this report is to review the relevant literature describing the endoscopic resection of intraventricular masses as a whole, both cystic and solid, to provide a better understanding of this technique's virtues and limitations.

\section{Materials and Methods}

Pubmed literature searches were performed using search terms "(endoscop") AND ventric", "(endoscop") AND 
tumor", "((neuro-endoscop*) OR neuroendoscop $\left.{ }^{*}\right)$ AND tumor", and "(tumor) AND ventric". Additional articles were located via cross-referencing of articles discovered initially through Pubmed searches. Articles included in the study were required to originate from peer-reviewed, English language journals describing the attempted resection (e.g., biopsies and cyst fenestrations without attempted resection were excluded) of an intraventricular tumor (e.g., suprasellar neoplasms without intraventricular extension were excluded) by purely endoscopic means (e.g., "endoscope-assisted" microsurgical resections were excluded) through a single endoscope ("dual-port" resections were excluded). Care was taken to exclude any redundant patient data from the analysis, and five articles required exclusion from the study due to an inability to definitively distinguish study patients in these five articles from patients in other study articles by the same author. In these five cases, the earlier of the two conflicting publications was omitted. Selected articles were also required to report on one or more of the following variables: (1) estimated completeness of resection achieved, (2) radiographic recurrence rates, and/or (3) complications related to the procedure. Cases involving the use of stereotactic radiosurgery, chemotherapy, or other nonsurgical treatment adjuncts were included. Two hundred and twenty articles were reviewed, and 40 were selected based on the above criteria.

Data collected from these 40 studies included tumor type, location within the ventricular system, tumor size, the presence of hydrocephalus preoperatively, operative technique, success of endoscopic resection, rates of intraoperative hemorrhage, and other procedure-related complications, rates of tumor recurrence, and length of clinical and/or radiographic follow-up.

Estimates regarding the completeness of endoscopic resection were obtained most commonly by surgeon or observer recollection and self-report, but were also obtained through assessments of postoperative imaging studies and chart review in some cases. Complete endoscopic resection was defined as gross total resection of all visible tumor as confirmed by visual intraoperative assessment or by the absence of any visible tumor residual on postoperative contrast magnetic resonance imaging (MRI). Near-complete resection was defined as resection of all but a very small amount of tumor adherent to nearby tissues. Partial resection was defined by a considerable tumor remnant as assessed either intraoperatively or on postoperative contrast MRI.

Statistical analysis was performed using the Student $t$-test and chi-square analysis using Microsoft Excel and GraphPad Instat 3 software. If the sample size was insufficient for chisquare testing $(n<5)$, the Fisher exact text was used. A $P$ value of 0.05 was considered statistically significant.

\section{Results}

3.1. Patients and Tumor Types. The entire patient population consisted of 668 patients with intraventricular tumors who underwent attempted endoscopic resection. The publication dates of the 40 articles ranged from 1994 to 2012, and the number of patients $(n)$ in each article ranged from 1 to 90 patients (mean, 16 patients). Hydrocephalus was seen preoperatively in 296 of 352 patients (84.1\%) for whom relevant data was reported.

Colloid cysts were the most frequently encountered tumor by far ( $n=569,85.2 \%$ of study patients) followed by hypothalamic hamartomas ( $n=30,4.5 \%$ of study patients), craniopharyngiomas ( $n=8,1.2 \%$ of study patients), and ependymomas ( $n=7,1.0 \%$ of study patients). In 14 patients ( $2.1 \%$ of study patients) from 3 articles, the histological tumor type was either unknown or not reported. Tumor diameter ranged from 0.5 to $4.5 \mathrm{~cm}$ in 274 tumors from series where tumor size was reported (mean diameter, $1.5 \mathrm{~cm}$ ). The most common tumor location was the third ventricle $(n=572$, $85.2 \%$ of reported locations). Patient information and tumor types are summarized in Tables 1 and 2, respectively.

3.2. Operative Technique. Various techniques for neuroendoscopic resection of intraventricular tumors have been described in detail elsewhere [2, 12, 16, 20, 25-35]. Individual techniques differed throughout the included studies between surgeons as well as variances in tumor morphology and patient anatomy.

All procedures were performed with the patient under general anesthesia in a supine position. The patient's head was most commonly placed on a soft headrest, except where neuronavigation or stereotaxy was used, in which case the patient's head was placed in a 3-point pin fixation device. Preoperative antibiotics were always administered, but prophylactic antiepileptics frequently were not. The average operative time was 107.5 minutes and the average hospital stay was $4.8 \pm 2.9$ days.

Ventricular access was most commonly attained through a right-sided approach (unless asymmetric left-sided ventriculomegaly was present, in which case a left-sided approach was preferred). In all cases of hypothalamic hamartoma resection, ventricular access was performed contralateral to the greatest extent of tumor mass. Incision was made over the intended ventricular access site and a standard burr hole was created. The burr hole was most commonly placed at some variant of Kocher's point, although slightly more lateral (5-7 cm lateral to midline) on occasion. [3, 11, 36] Several authors make note of the importance of beveling the burr hole into a conical shape to allow for a greater degree of scope manipulation and visualization during the procedure $[11,37]$. In some cases, the burr hole was placed more anteriorly (e.g., $5 \mathrm{~cm}$ anterior to the coronal suture, $n=183[25,26,30,31$, $38,39]$; or $1.5-3 \mathrm{~cm}$ above the orbital rim in cases where a supraorbital trajectory was used, $(n=8[27,40]))$ to allow for better visualization of more posteriorly located tumors. In two cases, ventricular access was obtained via a transcallosal approach [12], and in the case of two pineal masses [41], a subtorcular approach was used.

The dura is incised in cruciate fashion and coagulated, followed by ventricular puncture and the introduction of an endoscope. Often a small-diameter peel-away introducer sheath containing a navigation probe and/or small-diameter rigid endoscope is used for initial ventricular puncture, 
although some authors preferred to perform initial ventricular puncture with a ventricular needle or catheter, followed by the introduction of an endoscope into the needle or catheter tract $[31,33]$.

3.3. Instruments. After entry into the ventricle, the tumor is inspected and its relationship to the surrounding anatomy is assessed. In some cases, visualization required the use of a $30^{\circ}$ rigid endoscope or flexible neuroendoscope. A larger diameter rigid endoscope with multiple working channels is then introduced, through which tumor manipulation, coagulation, and resection take place. In the case of 59 colloid cysts and a single ependymoma, flexible neuroendoscopes were used for the majority of the procedure $[2,42,43]$.

Cystic tumors were frequently penetrated and gently aspirated, after which the cyst wall was coagulated and resected piecemeal or en bloc with forceps, scissors, and other tools. In several cases, an adjunctive endoscopic aspiration tool (CUSA (Tyco Healthcare Radionics, Burlington, MA, USA) $(n=2)$ [41], NICO Myriad aspirator (NICO Corporation, Indianapolis, IN, USA) $(n=9)$ [41, 44, 45], Micro ENP Ultrasonic Hand Piece (Scoring GmbH, Medizintechnik, Germany) ( $n=1)$ [42], or the Suros device (Suros Surgical Systems, Inc., Indianapolis, IN) $(n=2)[46])$ assisted with tumor debulking and removal.

3.4. Navigation/Stereotaxy. Navigation and/or stereotactic localization tools were used in 266 procedures $(45.1 \%$ of 581 procedures reporting such data) $[12,25-29,31,33-$ $35,38,39,42,46-49]$. In some cases, navigation and/or stereotactic tools were used only in those patients lacking ventriculomegaly on preoperative imaging, due to the enhanced difficulty associated with endoscopic visualization and maneuverability in the absence of hydrocephalus. A single author describes the intraventricular insufflation of saline in cases where small ventricles are encountered in attempts to improve operative success in this setting [28]. Data regarding the use of navigation or stereotactic tools is summarized in Table 1.

3.5. Completeness of Resection. Complete or near-complete tumor resection was achieved in 487 of 649 patients (75.0\%) for whom completeness of endoscopic resection was reported. Complete resections were seen after initial resection attempts in $80.2 \%$ of colloid cysts, compared with $45.5 \%$ of other tumors $(P<0.0001)$. Complete or near-complete resection was more commonly attained amongst tumors with a substantial cystic component $(79 \%)$ when compared with noncystic tumors $(38.2 \%)(P<0.0001)$. Complete or near-complete resection was also significantly more likely for tumors $\leq 2 \mathrm{~cm}$ in diameter when compared with larger tumors $(P=0.0146)$, and for tumors resected with the aid of navigation/stereotaxy $(P=0.0003)$ compared with those where these tools were not used. Resection outcomes are displayed in Figure 1 and Tables 1 and 2.

3.6. Adjunctive Procedures. Procedures in addition to the tumor resection were attempted during the same operative session in 70 patients $(12.0 \%$ of patients for whom such data was reported). These adjunctive procedures included endoscopic third ventriculostomy $(n=27)[12,16,19,29$, $30,42,49,50]$, septum pellucidostomy $(n=28)[12,36$, $49,51]$, stent placement within the foramen of Monro and/or aqueduct of Sylvius $(n=2)[12,19]$, placement of a VP-shunt [44] $(n=2)$, and postresection fluorescent ventriculography $(n=11)[34]$.

3.7. Procedure-Related Complications. Perioperative complications were seen in 123 out of 592 patients (20.8\%) for whom data regarding complications was reported. These complications included hemorrhage (intraventricular, $n=$ 41; intraparenchymal or along the introducer tract, $n=2$; or epidural, $n=2)$, meningitis and/or ventriculitis $(n=15)$, "memory disturbance" $(n=14)$, CSF leak $(n=6)$, infarct $(n=$ $5)$, cranial nerve deficit $(n=4)$, and hormonal disturbance $(n=2)$. The presence of a cystic component was associated with a significantly lower complication rate when compared to noncystic tumors $(P<0.0001)$. No significant relationship was observed between tumor size $(P=0.355)$ or the use of navigation/stereotaxy $(P=0.196)$ and complication rate. Data regarding procedure-related complications are shown in Figure 1 and Tables 1 and 2.

3.8. Clinical Outcomes. In the large majority of study patients, clinical morbidity was either unchanged or improved at most latent follow-up. There were no deaths reported to have occurred as a result of any of the 668 procedures. Postoperative morbidity increases were seen in 54 patients $(9.5 \%$ of 569 patients for whom the relevant data was supplied) due to a variety of complications, including post-operative infarct, intraventricular hemorrhage, and meningitis or ventriculitis. Clinical outcomes are summarized in Table 1.

3.9. Tumor Recurrence. Tumor recurrence was seen in 53 of the 533 patients (9.9\%) for whom data regarding recurrence was reported throughout an average of 31 months of followup. Recurrence was discovered, on average, 39 months after the initial resection in these 53 patients (range, 6-79 months). Tumor recurrence was seen in $9.8 \%$ of colloid cysts (49/498 patients reporting) compared with $11.1 \%$ of other tumors (4/36 patients reporting) $(P=0.805)$. Recurrence was seen most frequently with epidermoid cysts $(n=1,100 \%$ recurrence), craniopharyngiomas ( $n=5,40 \%$ recurrence), and ependymomas ( $n=1,14.3 \%$ recurrence). No significant relationship was observed between tumor size $(P=0.546)$ or the presence of a cystic component $(P=0.325)$ and recurrence rates. Data regarding tumor recurrence are seen in Figure 1 and Tables 1 and 2.

\section{Discussion}

4.1. Virtues of Neuroendoscopic Tumor Resection. Neuroendoscopy offers solutions to some of the challenges faced with intraventricular tumor surgery. Endoscopic approaches to intraventricular pathology provide improved illumination 


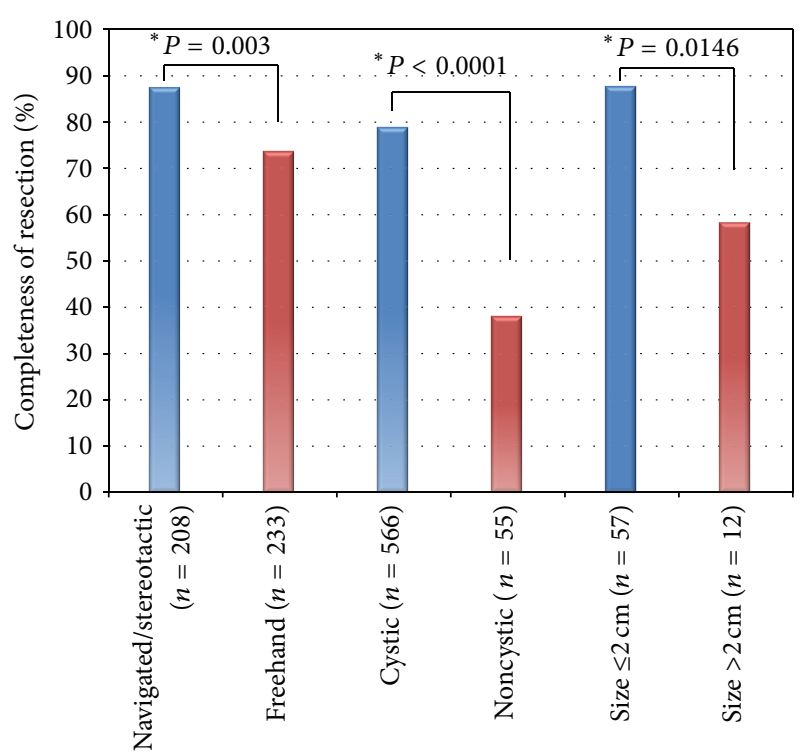

(a)

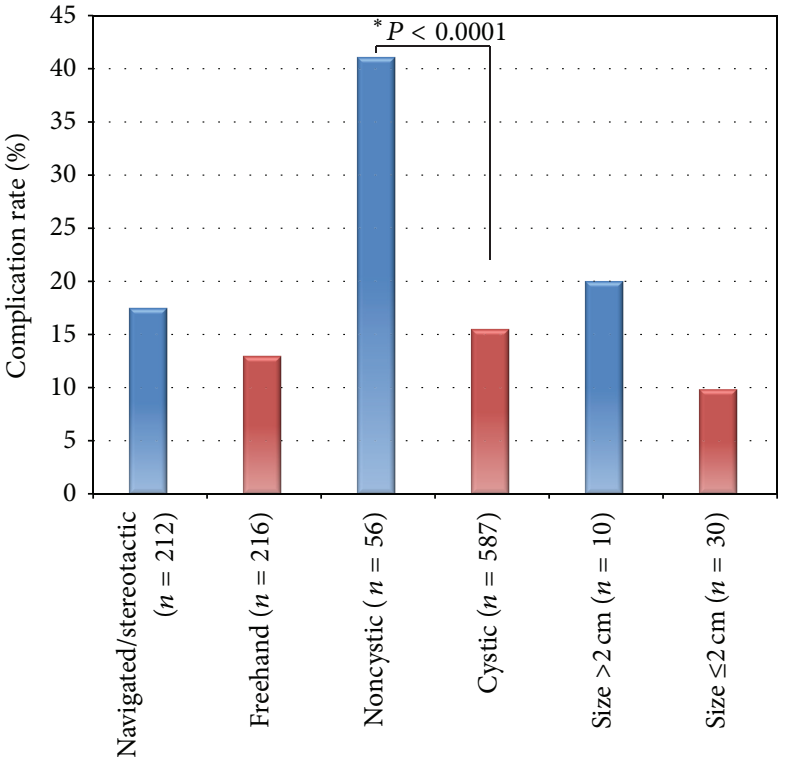

(b)

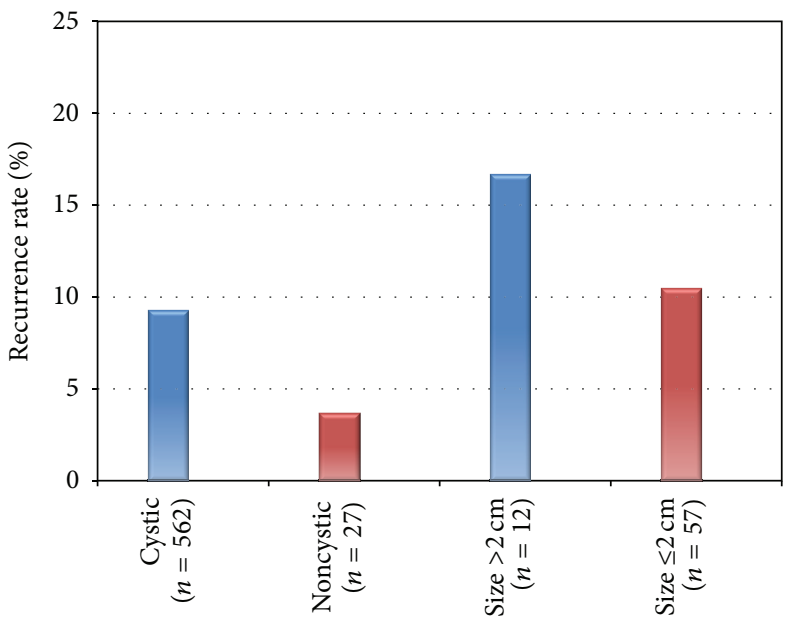

(c)

FIGURE 1: Column graphs displaying the variances in (a) resection success, (b) recurrence rate, and (c) complication rate seen with navigated endoscopic resection versus freehand, cystic tumors versus non-cystic, and large tumors (size $>2 \mathrm{~cm}$ ) versus small $($ size $\leq 2 \mathrm{~cm}) .{ }^{*}=$ statistically significant result.

and visualization of an anatomically remote and otherwisedifficult-to-reach location without the degree of tissue dissection and retraction often required with microsurgical techniques [24, 52]. Early results taken from colloid cyst resection demonstrate a reduction in complication rates, overall morbidity, operative time, and hospital stay [20-22, 25].

Neuroendoscopic approaches to intraventricular pathology also afford the surgeon an opportunity to treat associated hydrocephalus concomitantly, although tumor resection alone may be sufficient to restore cerebrospinal fluid (CSF) flow in some cases [12, 24, 53, 54]. In our study, hydrocephalus was seen on presentation in $84.1 \%$ of intraventricular tumors undergoing endoscopic resection, yet adjunctive cerebrospinal fluid (CSF) diversionary procedures were performed along with tumor resection in only $12.0 \%$.
4.2. Ideal Candidates for a Neuroendoscopic Approach. Neuroendoscopic resection appears to be most safe and effective $[2,21,25,34]$ when applied in a particular patient population and morphology of tumor. It is often suggested that small tumors, for example, are ideal candidates for neuroendoscopic resection [12, 23, 24, 32, 52]. Soft and/or cystic tumors are also preferred, as they lend themselves to rapid debulking via aspiration and/or other endoscopic techniques [12, 32]. Rigid tumors, in contrast, must be dissected and removed piecemeal with the fairly rudimentary tools available for endoscopic use. This may be too time-consuming of an endeavor to warrant the use of endoscopy in such cases. These principles appear substantiated by our findings that complete or near-complete resection was significantly more common for tumors with a large cystic component and those $\leq 2 \mathrm{~cm}$ in diameter. 


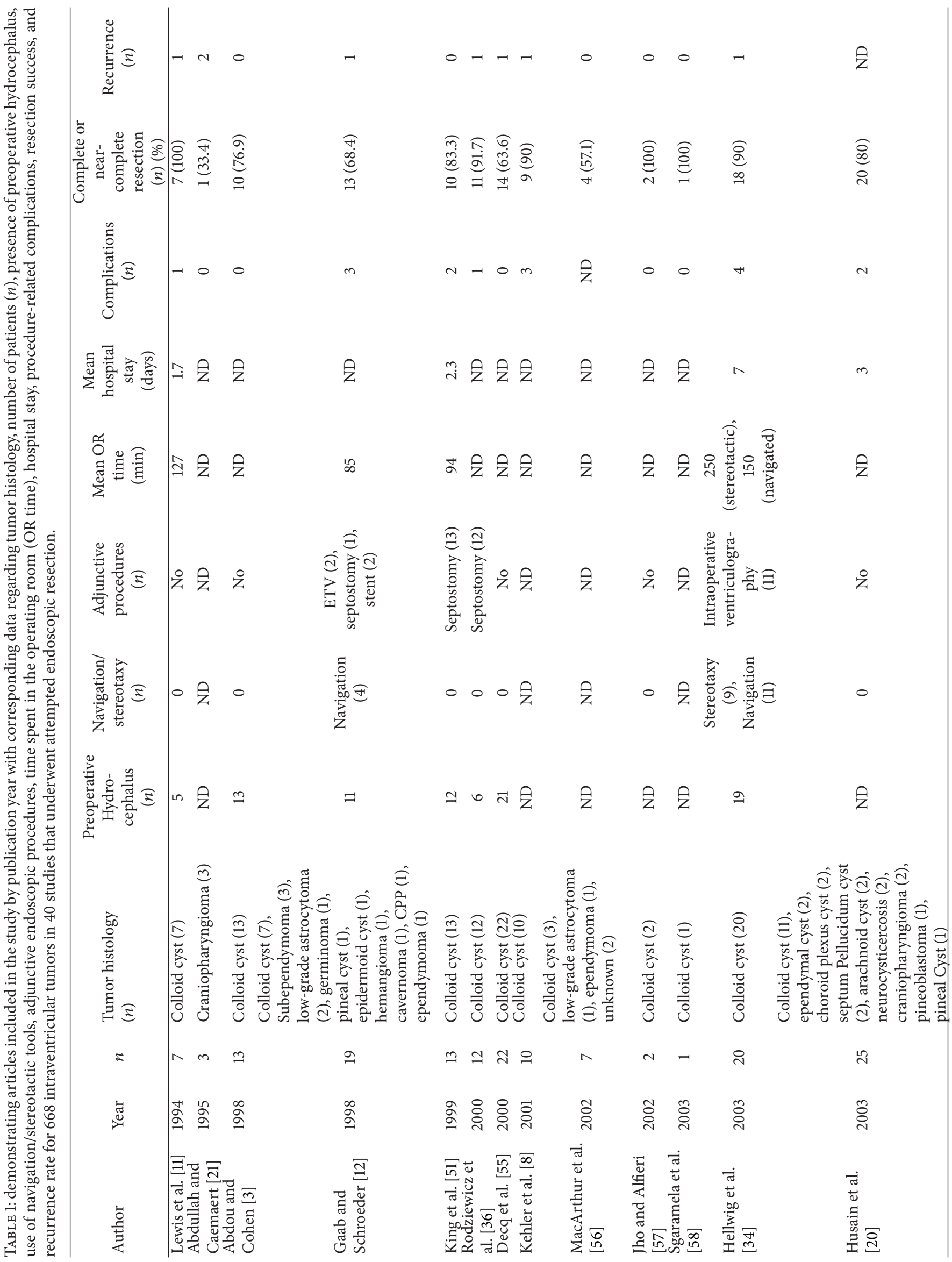




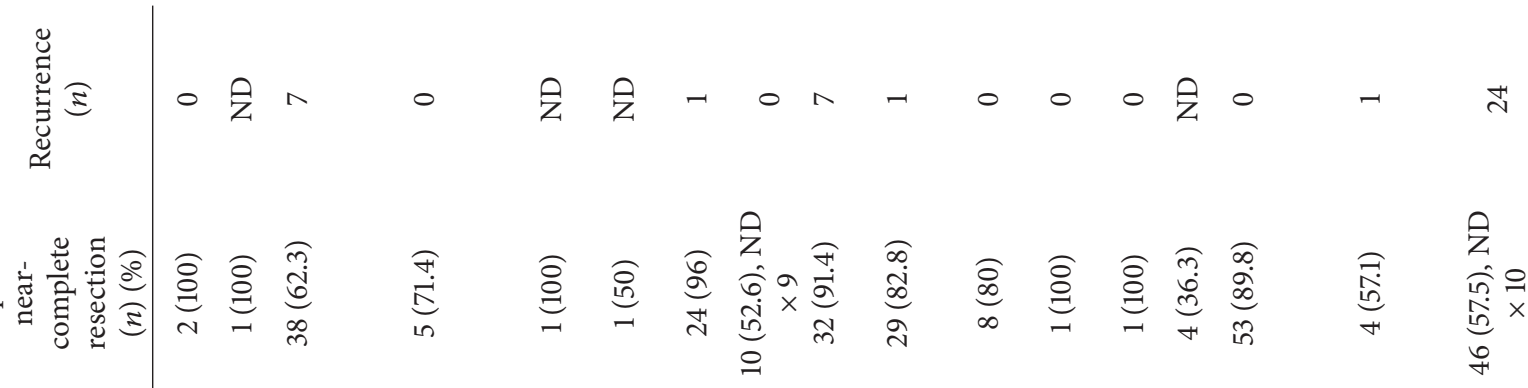

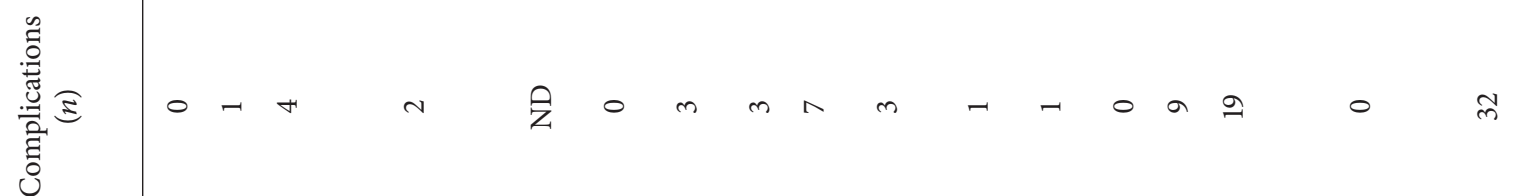

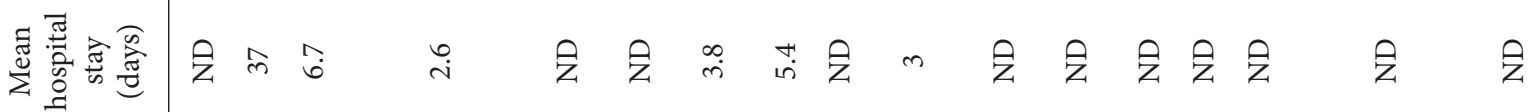

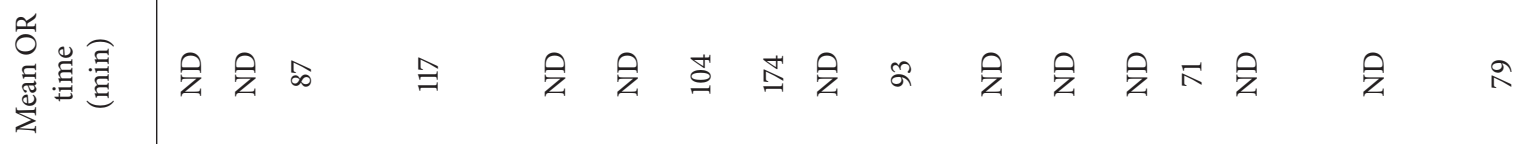

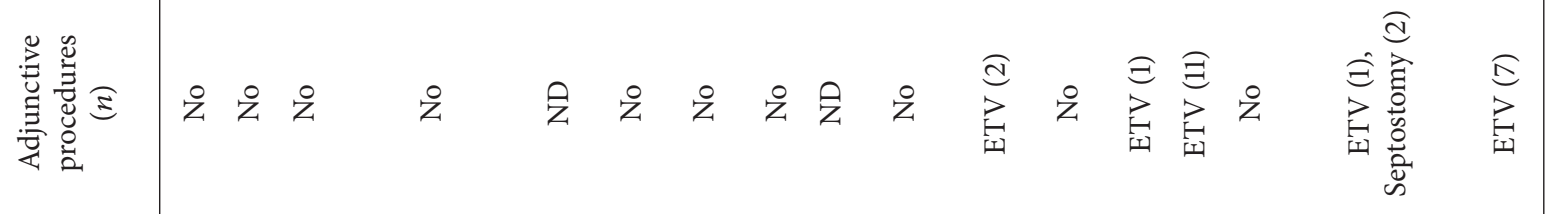

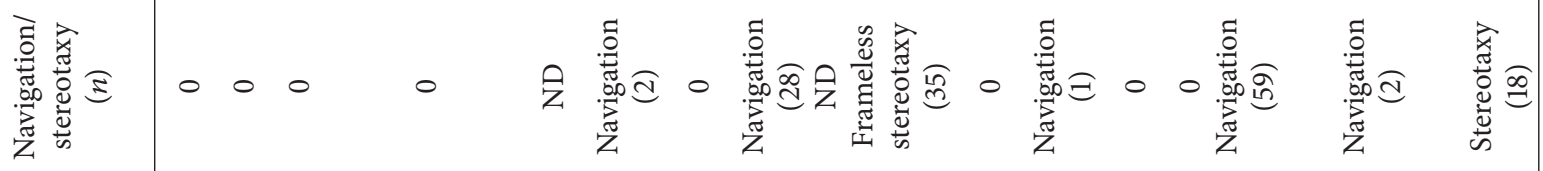

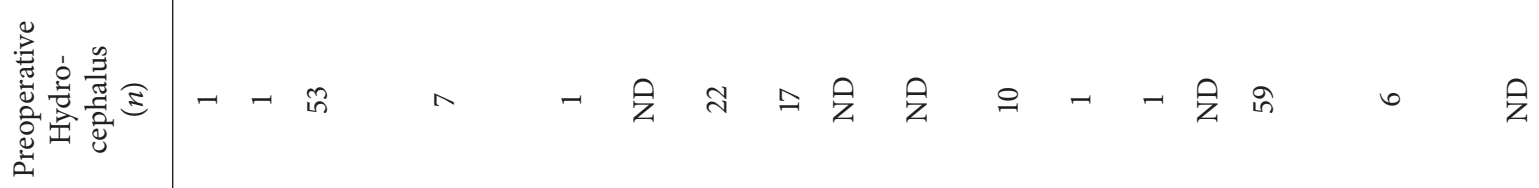

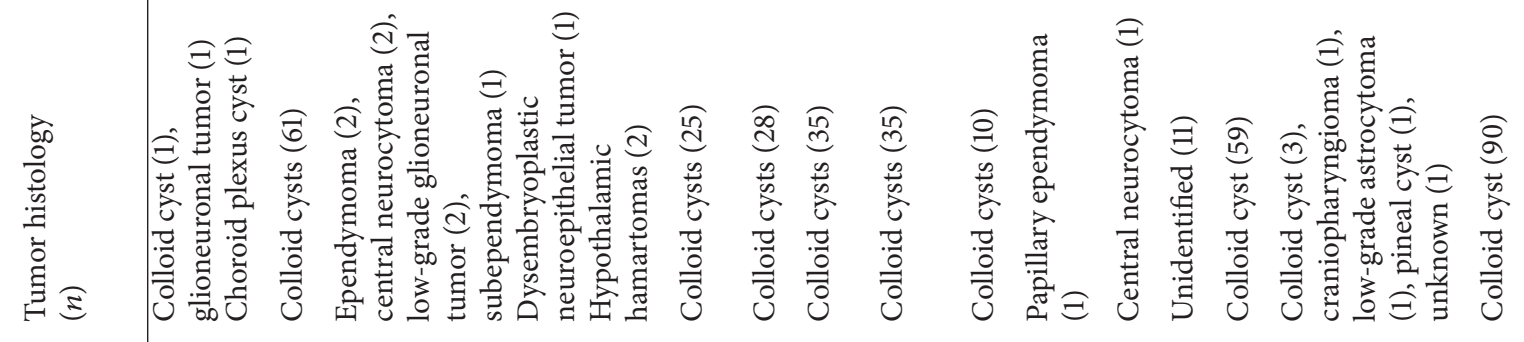

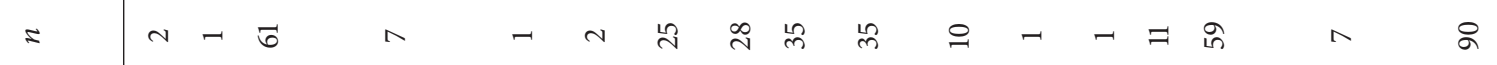

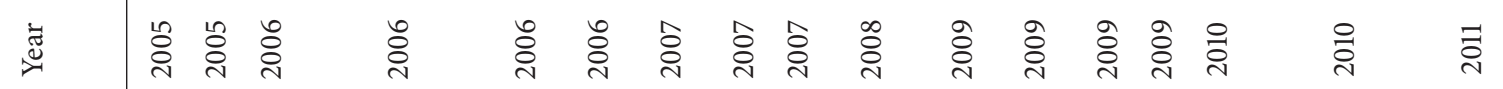

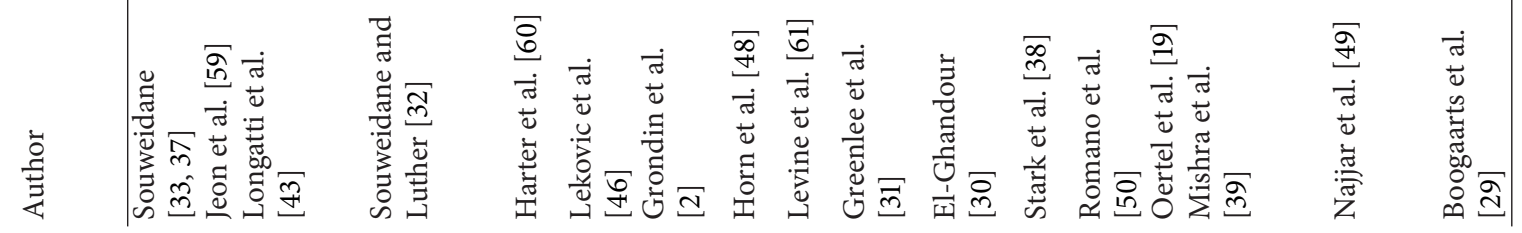




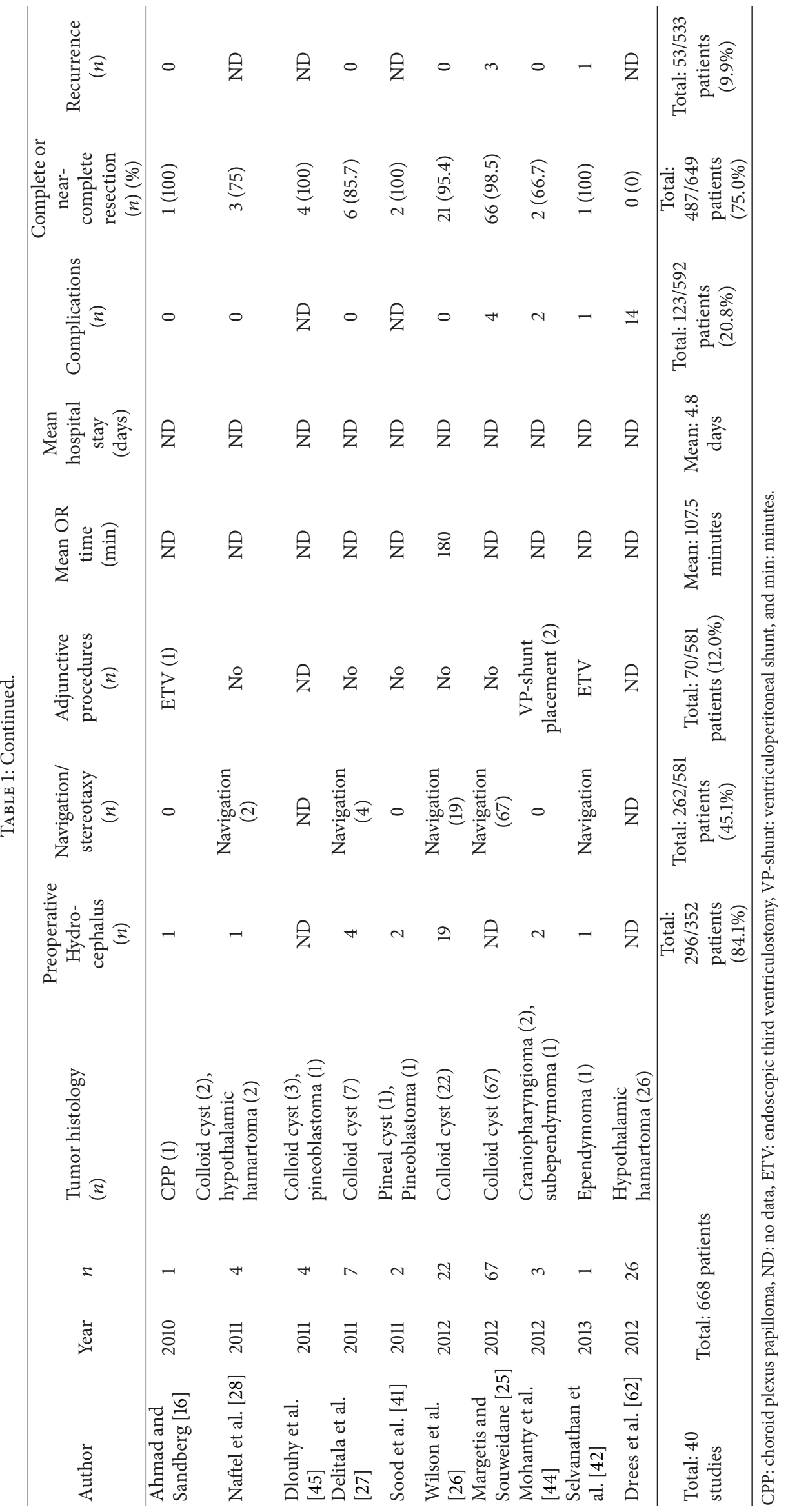


TABLE 2: displaying the various tumor histologies included in the study with corresponding data regarding the number of studies included, the number of patients, resection success, complication rates, and recurrence rates for each tumor type.

\begin{tabular}{|c|c|c|c|c|c|}
\hline Tumor histology & $\begin{array}{c}\text { Studied } \\
\text { included }(n)\end{array}$ & Patients $(n)$ & $\begin{array}{c}\text { Complete or } \\
\text { near-complete } \\
\text { resection }(n)(\%)\end{array}$ & $\begin{array}{l}\text { Complications } \\
(n)\end{array}$ & $\begin{array}{l}\text { Recurrence } \\
(n)\end{array}$ \\
\hline Colloid Cyst & 21 & 569 & $\begin{array}{c}\text { 441/550 patients } \\
(80.2 \%)\end{array}$ & $\begin{array}{c}\text { 83/556 patients } \\
(14.9 \%)\end{array}$ & $\begin{array}{c}\text { 49/498 patients } \\
(9.8 \%)\end{array}$ \\
\hline $\begin{array}{l}\text { Hypothalamic } \\
\text { hamartoma }\end{array}$ & 3 & 30 & $2 / 30$ patients $(6.7 \%)$ & $\begin{array}{l}\text { 14/30 patients } \\
(46.7 \%)\end{array}$ & ND \\
\hline Unidentified & 3 & 14 & $6 / 14$ patients $(42.8 \%)$ & $9 / 12$ patients $(75 \%)$ & $0 / 3$ patients $(0 \%)$ \\
\hline Craniopharyngioma & 4 & 8 & 4/8 patients $(50 \%)$ & $1 / 8$ patients $(12.5 \%)$ & $2 / 5$ patients $(40 \%)$ \\
\hline Ependymoma & 5 & 7 & $7 / 7$ patients $(100 \%)$ & $\begin{array}{c}\text { 4/6 patients } \\
(66.6 \%)\end{array}$ & $1 / 7$ patients $(14.3 \%)$ \\
\hline Subependymoma & 3 & 5 & $2 / 5$ patients $(40 \%)$ & $2 / 5$ patients $(40 \%)$ & $0 / 3$ patients $(0 \%)$ \\
\hline $\begin{array}{l}\text { Low-grade } \\
\text { astrocytoma }\end{array}$ & 3 & 4 & $1 / 4$ patients $(25 \%)$ & $0 / 3$ patients $(0 \%)$ & $0 / 4$ patients $(0 \%)$ \\
\hline Pineal cyst & 4 & 4 & $3 / 4$ patients $(75 \%)$ & $0 / 3$ patients $(0 \%)$ & $0 / 2$ patients $(0 \%)$ \\
\hline Pineoblastoma & 3 & 3 & $3 / 3$ patients $(100 \%)$ & $0 / 2$ patients $(0 \%)$ & ND \\
\hline Central neurocytoma & 2 & 3 & $2 / 3$ patients $(33.4 \%)$ & $0 / 3$ patients $(0 \%)$ & $0 / 3$ patients $(0 \%)$ \\
\hline Choroid plexus cyst & 2 & 3 & $3 / 3$ patients $(100 \%)$ & $1 / 3$ patients $(33.4 \%)$ & ND \\
\hline $\begin{array}{l}\text { Choroid plexus } \\
\text { papilloma }\end{array}$ & 2 & 2 & $2 / 2$ patients $(100 \%)$ & $0 / 2$ patients $(0 \%)$ & $0 / 2$ patients $(0 \%)$ \\
\hline $\begin{array}{l}\text { Septum pellucidum } \\
\text { cyst }\end{array}$ & 1 & 2 & $2 / 2$ patients $(100 \%)$ & $0 / 2$ patients $(0 \%)$ & $\mathrm{ND}$ \\
\hline Ependymal cyst & 1 & 2 & $2 / 2$ patients $(100 \%)$ & $0 / 2$ patients $(0 \%)$ & $\mathrm{ND}$ \\
\hline Arachnoid Cyst & 1 & 2 & $0 / 2$ patients $(0 \%)$ & $0 / 2$ patients $(0 \%)$ & ND \\
\hline Neurocysticercosis & 1 & 2 & $1 / 2$ patients $(50 \%)$ & $1 / 2$ patients $(50 \%)$ & ND \\
\hline $\begin{array}{l}\text { Neuroepithelial } \\
\text { tumor }\end{array}$ & 2 & 2 & $2 / 2$ patients $(100 \%)$ & $0 / 1$ patient $(0 \%)$ & $0 / 1$ patient $(0 \%)$ \\
\hline Glioneuronal tumor & 2 & 2 & $2 / 2$ patients $(100 \%)$ & $0 / 2$ patients $(0 \%)$ & $0 / 2$ patients $(0 \%)$ \\
\hline Cavernoma & 1 & 1 & 1/1 patient $(100 \%)$ & 1/1 patient $(100 \%)$ & $0 / 1$ patient $(0 \%)$ \\
\hline Hemangioma & 1 & 1 & 1/1 patient $(100 \%)$ & 0/1 patient $(0 \%)$ & $0 / 1$ patient $(0 \%)$ \\
\hline Epidermoid cyst & 1 & 1 & $0 / 1$ patient $(0 \%)$ & 1/1 patient $(100 \%)$ & $1 / 1$ patient $(100 \%)$ \\
\hline Germinoma & 1 & 1 & 1/1 patient $(100 \%)$ & 1/1 patient $(100 \%)$ & $0 / 1$ patient $(0 \%)$ \\
\hline
\end{tabular}

ND: no data.

Neuroendoscopic resection is also best suited for relatively avascular tumors $[23,24]$, as endoscopic methods of acquiring timely hemostasis are lacking, and endoscopic visualization is largely compromised in the setting of active, uncontrolled hemorrhage $[12,32]$. In our study, there was insufficient documentation of tumor vascularity within the included studies to draw meaningful conclusions about any relationship between tumor vascularity and variables such as resection success or complication rate.

Ventriculomegaly is another factor which favors a neuroendoscopic approach. Small ventricles are thought to be unfavorable for neuroendoscopy because visibility and maneuverability in this setting are greatly reduced $[12,24,63$, 64], although several series provide evidence that endoscopic therapies are equally feasible in the absence of hydrocephalus $[28,65,66]$.

4.3. Weaknesses of Neuroendoscopic Tumor Resection. Several of the limitations of neuroendoscopic tumor resection derive from a fundamental inadequacy of modern neuroendoscopic technology. As previously noted, solid masses greater than $2 \mathrm{~cm}$ in diameter, and those with considerable vascularity, are less amenable to neuroendoscopic resection due to the elementary nature of tools currently available for endoscopic dissection and hemostasis.

The large majority of cases included in this study used forceps, suction catheters, and bipolar cautery as the primary tools for dissection, resection, and hemostasis, respectively. Several series, however, report on the use of assistive devices (e.g., CUSA, NICO Myriad aspirator, Micro ENP Ultrasonic Hand Piece, and the Suros device) designed to allow for rapid tumor dissection and removal through an endoscopic approach. Although surgeons who use these devices frequently report their being helpful, objective data regarding their overall benefit is lacking [42, 44, 45]. No significant difference in success of resection, complication rate, or clinical outcome was seen in our study with the use of these 
assistive devices, although their use was likely too infrequent $(n=8)$ to draw conclusions.

Endoscopic tumor resections are also frequently said to result in inferior rates of gross total resection [25]. The resection rates demonstrated in our study $(75.0 \%)$ and others (71-100\%) [12, 32, 37, 65], however, appear comparable to those reported for microsurgical resection (80.4\%-96\%), particularly when endoscopic resection attempts are limited to tumors $\leq 2 \mathrm{~cm}$ in diameter (in which case resection rates in our analysis improve to $87.8 \%)[2,67]$.

Some apprehension about the use of endoscopy for tumor resection arises from the perception that tumors resected endoscopically are more likely to recur $[12,21]$. There is, in fact, some evidence that the risk of postoperative colloid cyst recurrence is higher with endoscopic resections compared with microsurgery [48]. Other series, however, have shown recurrence rates to be equivalent between the two [2]. The recurrence rate of $9.9 \%$ seen in our study is similar to rates reported for microsurgical resections $(0.0 \%-33 \%)$ [32, 6875], although reported recurrence rates vary widely and depend greatly on such variables as tumor type, completeness of initial resection, and the use of adjuvant therapies.

4.4. Stereotactic Tools and Neuronavigation. The use of stereotactic and/or neuronavigational guidance for endoscopic tumor resection is commonly reported in the neurosurgical literature, particularly in cases where ventriculomegaly is absent $[12,33,65,66,76-78]$. Some have adopted these adjunctive tools for assistance with burrhole placement, ventricular cannulation, and intraventricular navigation with the expectation that they will simplify the procedure and perhaps improve radiographic and clinical outcomes. Although incorporation of these tools into the procedure may prolong operative time and/or inflate surgical costs, several authors have declared their use to be of substantial benefit $[12,77-79]$. Neuronavigation and/or stereotactic techniques were used in $44.1 \%$ of the cases in our study, and their use was associated with a significantly higher rate of complete or near-complete tumor resection.

4.5. Complications. The overall complication rate of $20.8 \%$ seen in this study is consistent with values reported elsewhere for endoscopic resection (0-25\%) [12, 28, 32, 35, 48, 76] and comparable to rates reported for microsurgical interventions (4.3-29.3\%) [72, 80-84], although some reports of complications following microsurgical resection approach $70 \%[5,11]$. The complications seen most commonly in our study were intraventricular hemorrhage (which was frequently minor) and memory disturbance (which was often transient). Many of the complications observed did not translate into increased clinical morbidity, and most of the complication-related clinical morbidity resolved to some degree with time.

4.6. Study Limitations. We present the largest analysis to date of outcomes for endoscopic resection of intraventricular tumors. Limitations of this study include the following: (1) all included publications are retrospective and therefore subject to errors of confounding and bias. A more accurate comparison between surgical and endoscopic resection requires a prospective, randomized trial. (2) Data in our study is collected over an extended period of time. Being that endoscopic techniques have progressed appreciably over the last 25 years, our results may not provide an accurate assessment of the results attainable with modern techniques. A minor percentage of the data included in the study draws from resections utilizing flexible endoscopes, for example. Although some authors are proficient with flexible neuroendoscopes and have reported good outcomes with their use, modern rigid endoscopes offer a vastly improved image quality and are preferred by many neurosurgeons. (3) Available data in the literature draws largely from series of endoscopic colloid cyst resection and thus, represent a slightly skewed picture of endoscopic tumor resection. More data are needed regarding endoscopic resection of other tumor histologies if we hope to gain a truly accurate and complete understanding of the advantages and disadvantages of this technique. (4) Finally, the large majority of cases of endoscopic resection of intraventricular tumors in the literature describe tumors in the region of the third ventricle. The majority of intraventricular tumors, however, are discovered in the body or frontal horn of the lateral ventricle, followed by the atrium, and finally, the foramen of Monro and third ventricle [80, 81, 85]. More data may be needed regarding endoscopic resection of tumors in these more common locations before comments regarding the safety, efficacy, and overall usefulness of endoscopy in the treatment of intraventricular masses can be made.

\section{Conclusion}

The goal of this study was to better characterize the advantages and disadvantages of the endoscopic approach to intraventricular tumors. Our results indicate that endoscopic tumor resection, when applied in the appropriate setting, is safe and effective.

Further improvements in the outcomes of neuroendoscopic tumor resection rely heavily on the development of endoscopic technology. Dissection tools allowing for the rapid and safe removal of large, solid tumors are lacking, as are effective means of acquiring prompt hemostasis through an endoscopic approach. More data is needed on the outcomes of endoscopic resection of tumors other than colloid cysts. Finally, randomized trials comparing surgical and endoscopic tumor resections would provide a better characterization of the virtues and limitations of each technique.

Microsurgical resection remains the gold standard of intraventricular tumor resection [1-4]. Endoscopic tools and techniques are improving, however, and the applications of endoscopy in the treatment of CNS pathology continue to expand. Though initial results appear promising, the potential of neuroendoscopy and its role in the management of intraventricular tumors are yet to be defined.

\section{Conflict of Interests}

The authors have no financial or any other conflict of interests to disclose. Specifically, the authors have no direct financial 
relationship to any commercial entities mentioned within the paper.

\section{References}

[1] M. Gazi Yaşargil and S. I. Abdulrauf, "Surgery of intraventricular tumors," Neurosurgery, vol. 62, no. 6, pp. SHC1029SHC1040, 2008.

[2] R. T. Grondin, W. Hader, M. E. MacRae, and M. G. Hamilton, "Endoscopic versus microsurgical resection of third ventricle colloid cysts," Canadian Journal of Neurological Sciences, vol. 34, no. 2, pp. 197-207, 2007.

[3] M. S. Abdou and A. R. Cohen, "Endoscopic treatment of colloid cysts of the third ventricle," Journal of Neurosurgery, vol. 89, no. 6, pp. 1062-1068, 1998.

[4] A. Goel, "Can the hype of, "Endoscope" become a reality for colloid cyst surgery?” World Neurosurg, no. 12, 2012.

[5] B. D. Milligan and F. B. Meyer, "Morbidity of transcallosal and transcortical approaches to lesions in and around the lateral and third ventricles: a single-institution experience," Neurosurgery, vol. 67, no. 6, pp. 1483-1496, 2010.

[6] R. L. Jeffree and M. Besser, "Colloid cyst of the third ventricle: a clinical review of 39 cases," Journal of Clinical Neuroscience, vol. 8, no. 4, pp. 328-331, 2001.

[7] K. I. Desai, T. D. Nadkarni, D. P. Muzumdar, and A. H. Goel, "Surgical management of colloid cyst of the third ventricle-a study of 105 cases," Surgical Neurology, vol. 57, no. 5, pp. 295$302,2002$.

[8] U. Kehler, A. Brunori, J. Gliemroth et al., "Twenty colloid cysts-comparison of endoscopic and microsurgical management," Minimally Invasive Neurosurgery, vol. 44, no. 3, pp. 121127, 2001.

[9] J.-P. Lejeune, D. Le Gars, and E. Haddad, “Tumors of the third ventricle: review of 262 cases," Neurochirurgie, vol. 46, no. 3, pp. 211-238, 2000.

[10] T. Mathiesen, P. Grane, L. Lindgren, and C. Lindquist, "Third ventricle colloid cysts: a consecutive 12-year series," Journal of Neurosurgery, vol. 86, no. 1, pp. 5-12, 1997.

[11] A. I. Lewis, K. R. Crone, J. Taha, H. R. Van Loveren, H.-S. Yeh, and J. M. Tew Jr., "Surgical resection of third ventricle colloid cysts. Preliminary results comparing transcallosal microsurgery with endoscopy," Journal of Neurosurgery, vol. 81, no. 2, pp. 174$178,1994$.

[12] M. R. Gaab and H. W. S. Schroeder, "Neuroendoscopic approach to intraventricular lesions," Journal of Neurosurgery, vol. 88, no. 3, pp. 496-505, 1998.

[13] W. Dandy, Cerebral Ventriculoscopy, vol. 33, Bull Johns Hopkins Hosp, 1922.

[14] L. Davis, Neurological Surgery, Lea \& Febiger, Philadelphia, Pa, USA, 1936.

[15] Y. Enchev and S. Oi, "Historical trends of neuroendoscopic surgical techniques in the treatment of hydrocephalus," Neurosurgical Review, vol. 31, no. 3, pp. 249-261, 2008.

[16] F. Ahmad and D. I. Sandberg, "Endoscopic management of intraventricular brain tumors in pediatric patients: a review of indications, techniques, and outcomes," Journal of Child Neurology, vol. 25, no. 3, pp. 359-367, 2010.

[17] S. Kunwar, "Endoscopic adjuncts to intraventricular surgery," Neurosurgery Clinics of North America, vol. 14, no. 4, pp. 547$557,2003$.
[18] F. E. Nulsen and E. B. Spitz, "Treatment of hydrocephalus by direct shunt from ventricle to jugular vain," Surgical forum, pp. 399-403, 1951.

[19] J. M. K. Oertel, J. Baldauf, H. W. S. Schroeder, and M. R. Gaab, "Endoscopic options in children: experience with 134 procedures: clinical article," Journal of Neurosurgery: Pediatrics, vol. 3, no. 2, pp. 81-89, 2009.

[20] M. Husain, D. Jha, D. K. Vatsal et al., "Neuro-endoscopic surgery-experience and outcome analysis of 102 consecutive procedures in a busy neurosurgical centre of India," Acta Neurochirurgica, vol. 145, no. 5, pp. 369-376, 2003.

[21] J. Abdullah and J. Caemaert, "Endoscopic management of craniopharyngiomas: a review of 3 cases," Minimally Invasive Neurosurgery, vol. 38, no. 2, pp. 79-84, 1995.

[22] D. Hellwig and B. L. Bauer, "Minimally invasive neurosurgery by means of ultrathin endoscopes," Acta Neurochirurgica, vol. 54, pp. 63-68, 1992.

[23] P. Cappabianca, G. Cinalli, M. Gangemi et al., "Application of neuroendoscopy to intraventricular lesions," Neurosurgery, vol. 62, no. 2, pp. SHC575-SHC597, 2008.

[24] C. Teo and P. Nakaji, "Neuro-oncologic applications of endoscopy," Neurosurgery Clinics of North America, vol. 15, no. 1, pp. 89-103, 2004.

[25] K. Margetis and M. M. Souweidane, Endoscopic Treatment of Intraventricular Cystic Tumors, World Neurosurg, 2012.

[26] D. A. Wilson, D. J. Fusco, S. D. Wait, and P. Nakaji, Endoscopic Resection of Colloid Cysts: Use of A Dual-Instrument Technique and an Anterolateral Approach, World Neurosurg, 2012.

[27] A. Delitala, A. Brunori, and N. Russo, "Supraorbital endoscopic approach to colloid cysts," Neurosurgery, vol. 69, no. 2, pp. 176182, 2011.

[28] R. P. Naftel, C. N. Shannon, G. T. Reed et al., "Small-ventricle neuroendoscopy for pediatric brain tumor management: clinical article," Journal of Neurosurgery, vol. 7, no. 1, pp. 104-110, 2011.

[29] H. D. Boogaarts, P. Decq, J. A. Grotenhuis et al., "Long-term results of the neuroendoscopic management of colloid cysts of the third ventricle: a series of 90 cases," Neurosurgery, vol. 68, no. 1, pp. 179-187, 2011.

[30] N. M. F. El-Ghandour, "Endoscopic treatment of third ventricular colloid cysts: a review including ten personal cases," Neurosurgical Review, vol. 32, no. 4, pp. 395-402, 2009.

[31] J. D. W. Greenlee, C. Teo, A. Ghahreman, and B. Kwok, "Purely endoscopic resection of colloid cysts," Neurosurgery, vol. 62, no. 3, pp. ONS51-ONS55, 2008.

[32] M. M. Souweidane and N. Luther, "Endoscopic resection of solid intraventricular brain tumors," Journal of Neurosurgery, vol. 105, no. 2, pp. 271-278, 2006.

[33] M. M. Souweidane, "Endoscopic surgery for intraventricular brain tumors in patients without hydrocephalus," Neurosurgery, vol. 57, no. 4, pp. S312-S317, 2005.

[34] D. Hellwig, B. L. Bauer, M. Schulte et al., "Neuroendoscopic treatment for colloid cysts of the third ventricle: the experience of a decade," Neurosurgery, vol. 52, no. 3, pp. 525-533, 2003.

[35] H. W. S. Schroeder, M. R. Gaab, and A. R. Cohen, "Endoscopic resection of colloid cysts," Neurosurgery, vol. 51, no. 6, pp. 14411445, 2002.

[36] G. S. Rodziewicz, M. V. Smith, and C. J. Hodge Jr., "Endoscopic colloid cyst surgery," Neurosurgery, vol. 46, no. 3, pp. 655-662, 2000 . 
[37] M. M. Souweidane, "Endoscopic management of pediatric brain tumors," Neurosurgical Focus, vol. 18, no. 6, p. E1, 2005.

[38] A. M. Stark, H. H. Hugo, A. Nabavi, and H. M. Mehdorn, "Papillary ependymoma WHO grade II of the aqueduct treated by endoscopic tumor resection," Case Reports in Medicine, vol. 2009, Article ID 434905, 5 pages, 2009.

[39] S. Mishra, S. P. S. Chandra, A. Suri, K. Rajender, B. S. Sharma, and A. K. Mahapatra, "Endoscopic management of third ventricular colloid cysts: eight years' institutional experience and description of a new technique," Neurology India, vol. 58, no. 3, pp. 412-417, 2010.

[40] Z. Horváth, F. Vetö, I. Balás, and T. Dóczi, “Complete removal of colloid cyst via CT-guided stereotactic biportal neuroendoscopy," Acta Neurochirurgica, vol. 142, no. 5, pp. 539-546, 2000.

[41] S. Sood, M. Hoeprich, and S. D. Ham, "Pure endoscopic removal of pineal region tumors," Child's Nervous System, vol. 27, no. 9, pp. 1489-1492, 2011.

[42] S. K. Selvanathan, R. Kumar, J. Goodden, A. Tyagi, and P. Chumas, "Evolving instrumentation for endoscopic tumour removal of CNS tumours," Acta Neurochirurgica, vol. 155, no. 1, pp. 135-138, 2013.

[43] P. Longatti, U. Godano, M. Gangemi et al., "Cooperative study by the Italian neuroendoscopy group on the treatment of 61 colloid cysts," Child's Nervous System, vol. 22, no. 10, pp. 12631267, 2006.

[44] A. Mohanty, B. J. Thompson, and J. Patterson, "Initial experience with endoscopic side cutting aspiration system in pure neuroendoscopic excision of large intraventricular tumors," World Neurosurgery, 2012.

[45] B. J. Dlouhy, N. S. Dahdaleh, and J. D. W. Greenlee, "Emerging technology in intracranial neuroendoscopy: application of the NICO Myriad Technical note," Neurosurgical Focus, vol. 30, no. 4, article E6, 2011.

[46] G. P. Lekovic, L. F. Gonzalez, I. Feiz-Erfan, and H. L. Rekate, "Endoscopic resection of hypothalamic hamartoma using a novel variable aspiration tissue resector," Neurosurgery, vol. 58, no. 1, pp. S166-S168, 2006.

[47] N. Luther and M. M. Souweidane, "Neuroendoscopic resection of posterior third ventricular ependymoma. Case report," Neurosurgical Focus, vol. 18, no. 6 A, p. E3, 2005.

[48] E. M. Horn, I. Feiz-Erfan, R. E. Bristol et al., "Treatment options for third ventricular colloid cysts: comparison of open microsurgical versus endoscopic resection," Neurosurgery, vol. 60, no. 4, pp. 613-618, 2007.

[49] M. W. Najjar, N. I. Azzam, T. S. Baghdadi, A. H. Turkmani, and G. Skaf, "Endoscopy in the management of intra-ventricular lesions: preliminary experience in the Middle East," Clinical Neurology and Neurosurgery, vol. 112, no. 1, pp. 17-22, 2010.

[50] A. Romano, S. Chibbaro, O. Makiese, M. Marsella, P. Mainini, and E. Benericetti, "Endoscopic removal of a central neurocytoma from the posterior third ventricle," Journal of Clinical Neuroscience, vol. 16, no. 2, pp. 312-316, 2009.

[51] W. A. King, J. S. Ullman, J. G. Frazee, K. D. Post, and M. Bergsneider, "Endoscopic resection of colloid cysts: surgical considerations using the rigid endoscope," Neurosurgery, vol. 44, no. 5, pp. 1103-1111, 1999.

[52] H. W. Schroeder, Intraventricular Tumors, World Neurosurg, 2013.

[53] K. Oka, M. Yamamoto, S. Nagasaka, and M. Tomonaga, "Endoneurosurgical treatment for hydrocephalus caused by intraventricular tumors," Child's Nervous System, vol. 10, no. 3, pp. 162-166, 1994.

[54] Y. Zhang, C. Wang, P. Liu, and X. Gao, "Clinical application of neuroendoscopic techniques," Stereotactic and Functional Neurosurgery, vol. 75, no. 2-3, pp. 133-141, 2000.

[55] P. Decq, C. Le Guerinel, L. Sakka et al., "Endoscopic surgery of third ventricle lesions," Neurochirurgie, vol. 46, no. 3, pp. $286-$ 294, 2000.

[56] D. C. Macarthur, N. Buxton, J. Punt, M. Vloeberghs, and I. J. Robertson, "The role of neuroendoscopy in the management of brain tumours," British Journal of Neurosurgery, vol. 16, no. 5, pp. 465-470, 2002.

[57] H. D. Jho and A. Alfieri, "Endoscopic removal of third ventricular tumors: a technical note," Minim Invasive Neurosurg, vol. 45, no. 2, pp. 114-119, 2002.

[58] E. Sgaramella, S. Sotgiu, and F. M. Crotti, "Neuroendoscopy: one year of experience-personal results, observations and limits," Minim Invasive Neurosurg, vol. 46, no. 4, pp. 215-219, 2003.

[59] J. H. Jeon, S. W. Lee, J. K. Ko et al., "Neuroendoscopic removal of large choroid plexus cyst: a case report," Journal of Korean Medical Science, vol. 20, no. 2, pp. 335-339, 2005.

[60] D. H. Harter, I. Omeis, S. Forman, and A. Braun, "Endoscopic resection of an intraventricular dysembryoplastic neuroepithelial tumor of the septum pellucidum," Pediatric Neurosurgery, vol. 42, no. 2, pp. 105-107, 2006.

[61] N. B. Levine, M. N. Miller, and K. R. Crone, "Endoscopic resection of colloid cysts: indications, technique, and results during a 13-year period," Minim Invasive Neurosurg, vol. 50, no. 6, Article ID 993215, pp. 313-317, 2007.

[62] C. Drees, K. Chapman, E. Prenger et al., "Seizure outcome and complications following hypothalamic hamartoma treatment in adults: endoscopic, open, and Gamma Knife procedures," Journal of Neurosurgery, vol. 117, no. 2, Article ID 112256, pp. 255-261, 2012.

[63] P. Grunert, N. Hopf, and A. Perneczky, "Frame-based and frameless endoscopic procedures in the third ventricle," Stereotactic and Functional Neurosurgery, vol. 68, no. 1-4, pp. 80-89, 1997.

[64] M. J. Torrens, "Endoscopic neurosurgery," Neurosurgery Quarterly, vol. 5, no. 1, pp. 18-33, 1995.

[65] M. M. Souweidane, "Endoscopic surgery for intraventricular brain tumors in patients without hydrocephalus," Neurosurgery, vol. 62, no. 6, pp. SHC1042-SHC1047, 2008.

[66] M. Yamamoto, K. Oka, S. Takasugi, S. Hachisuka, E. Miyake, and M. Tomonaga, "Flexible neuroendoscopy for percutaneous treatment of intraventricular lesions in the absence of hydrocephalus," Minimally Invasive Neurosurgery, vol. 40, no. 4, pp. 139-143, 1997.

[67] T. Hori, T. Kawamata, K. Amano, Y. Aihara, M. Ono, and N. Miki, "Anterior interhemispheric approach for 100 tumors in and around the anterior third ventricle," Neurosurgery, vol. 66, no. 3, pp. 65-74, 2010.

[68] G. Kaur, A. J. Kane, M. E. Sughrue et al., "MIB-1 labeling index predicts recurrence in intraventricular central neurocytomas," Journal of Clinical Neuroscience, vol. 20, no. 1, pp. 89-93, 2013.

[69] V. V. Nayar, F. DeMonte, D. Yoshor, J. B. Blacklock, and R. Sawaya, "Surgical approaches to meningiomas of the lateral ventricles," Clinical Neurology and Neurosurgery, vol. 112, no. 5, pp. 400-405, 2010. 
[70] A. Nowak and A. Marchel, "Surgical treatment of intraventricular ependymomas and subependymomas," Neurologia I Neurochirurgia Polska, vol. 46, no. 4, pp. 333-343, 2012.

[71] J. Pan, S. Qi, Y. Lu et al., "Intraventricular craniopharyngioma: morphological analysis and outcome evaluation of 17 cases," Acta Neurochirurgica, vol. 153, no. 4, pp. 773-784, 2011.

[72] H. Qian, S. Lin, M. Zhang, and Y. Cao, "Surgical management of intraventricular central neurocytoma: 92 cases," Acta Neurochirurgica, vol. 154, no. 11, pp. 1951-1960, 2012.

[73] H. I. Seçer, B. Düz, Y. Izci, Ö. Tehli, I. Solmaz, and E. Gönüls, "Tumors of the lateral ventricle: the factors that affected the preference of the surgical approach in 46 patiens," Turkish Neurosurgery, vol. 18, no. 4, pp. 345-355, 2008.

[74] K. Stachura, W. Libionka, M. Moskała, M. Krupa, and J. Polak, "Colloid cysts of the third ventricle. Endoscopic and open microsurgical management," Neurologia I Neurochirurgia Polska, vol. 43, no. 3, pp. 251-257, 2009.

[75] A. Vasiljevic, P. François, A. Loundou et al., "Prognostic factors in central neurocytomas: a multicenter study of 71 cases," The American journal of surgical pathology, vol. 36, no. 2, pp. 220227, 2012.

[76] H. L. Rekate, I. Feiz-Erfan, Y.-T. Ng, L. F. Gonzalez, and J. F. Kerrigan, "Endoscopic surgery for hypothalamic hamartomas causing medically refractory gelastic epilepsy," Child's Nervous System, vol. 22, no. 8, pp. 874-880, 2006.

[77] P. Decq, "Endoscopy or microsurgery: is the never-ending debate concerning the choice of surgical strategy for colloid cysts of the third ventricle still a topical issue or has it been resolved?" World Neurosurg, 2012.

[78] H. W. S. Schroeder, W. Wagner, W. Tschiltschke, and M. R. Gaab, "Frameless neuronavigation in intracranial endoscopic neurosurgery," Journal of Neurosurgery, vol. 94, no. 1, pp. 72-79, 2001.

[79] V. Rohde, T. Behm, H. Ludwig, and D. Wachter, "The role of neuronavigation in intracranial endoscopic procedures," Neurosurgical Review, vol. 35, pp. 351-358, 2012.

[80] H. Z. Gökalp, N. Yüceer, E. Arasil et al., "Tumours of the lateral ventricle. A retrospective review of 112 cases operated upon 1970-1997," Neurosurgical Review, vol. 21, no. 2-3, pp. 126-137, 1998.

[81] G. Pendl, E. Ozturk, and K. Haselsberger, "Surgery of tumours of the lateral ventricle," Acta Neurochirurgica, vol. 116, no. 2-4, pp. 128-136, 1992.

[82] J. M. Pascual, F. González-Llanos, L. Barrios, and J. M. Roda, "Intraventricular craniopharyngiomas: topographical classification and surgical approach selection based on an extensive overview," Acta Neurochirurgica, vol. 146, no. 8, pp. 785-800, 2004.

[83] S. Shapiro, R. Rodgers, M. Shah, D. Fulkerson, and R. L. Campbell, "Interhemispheric transcallosal subchoroidal fornixsparing craniotomy for total resection of colloid cysts of the third ventricle: clinical article," Journal of Neurosurgery, vol. 110, no. 1, pp. 112-115, 2009.

[84] R. Sampath, P. Vannemreddy, and A. Nanda, "Microsurgical excision of colloid cyst with favorable cognitive outcomes and short operative time and hospital stay: operative techniques and analyses of outcomes with review of previous studies," Neurosurgery, vol. 66, no. 2, pp. 368-374, 2010.

[85] J. Piepmeier, D. D. Spencer, K. J. Sass, and T. M. George, "Lateral ventricular masses," in Brain Surgery: Complication Avoidance and Management, M. Apuzzo, Ed., pp. 581-599, Churchhill Livingstone, New York, NY, USA, 1993. 


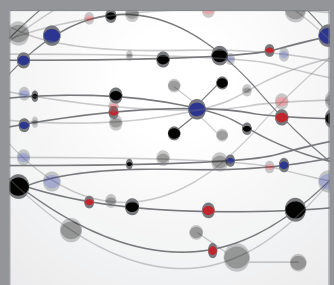

The Scientific World Journal
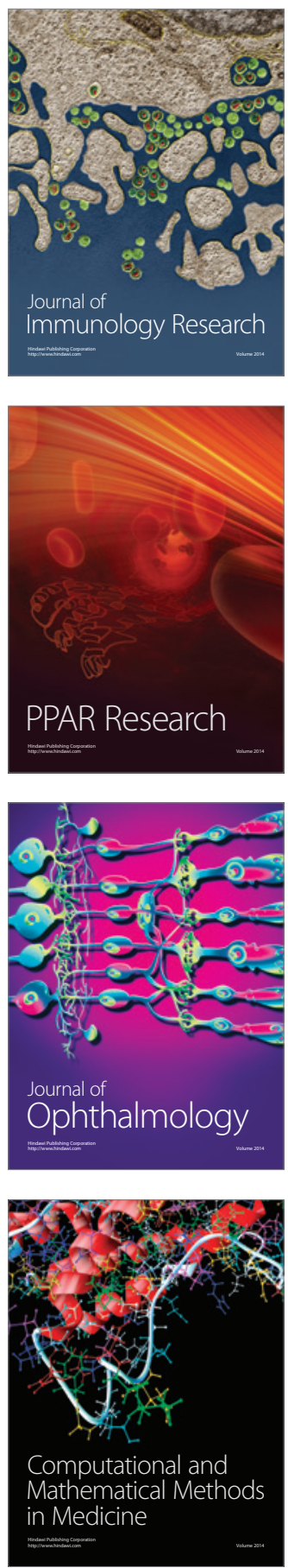

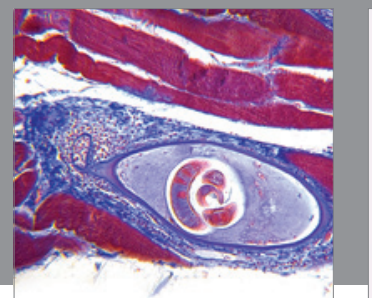

Gastroenterology

Research and Practice
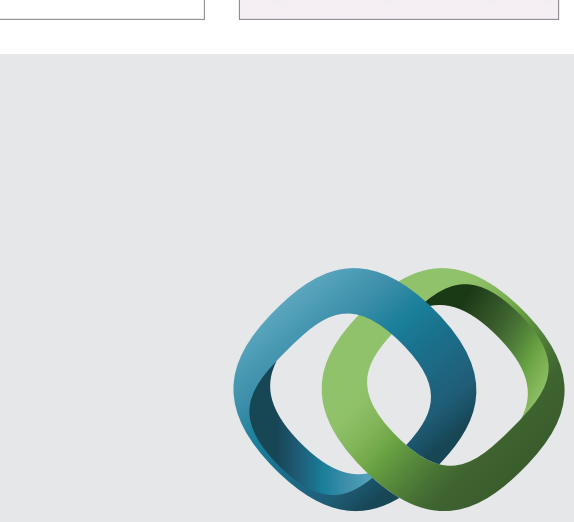

\section{Hindawi}

Submit your manuscripts at

http://www.hindawi.com
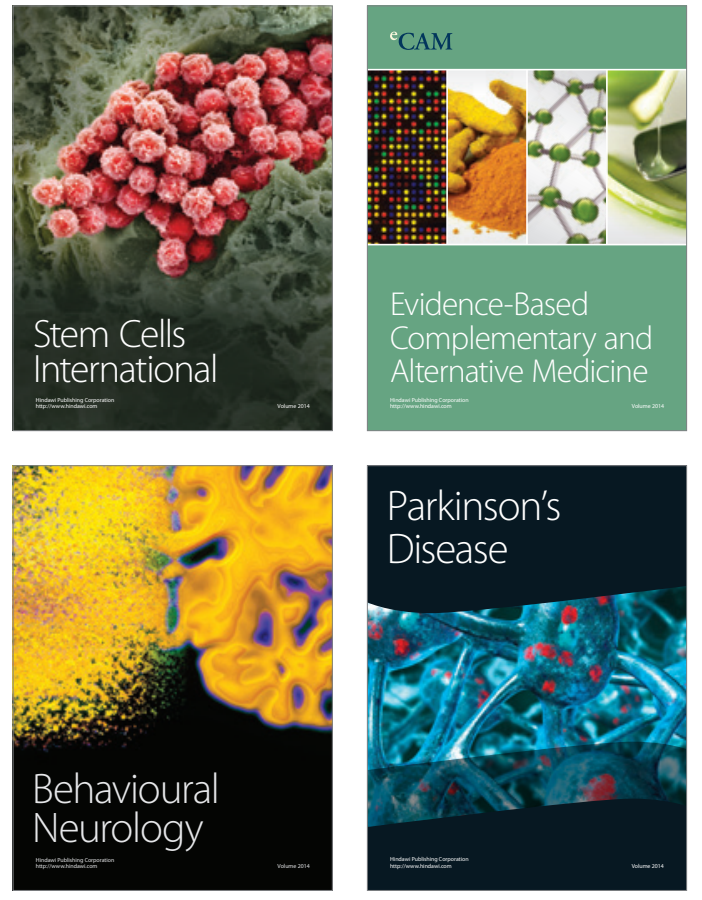
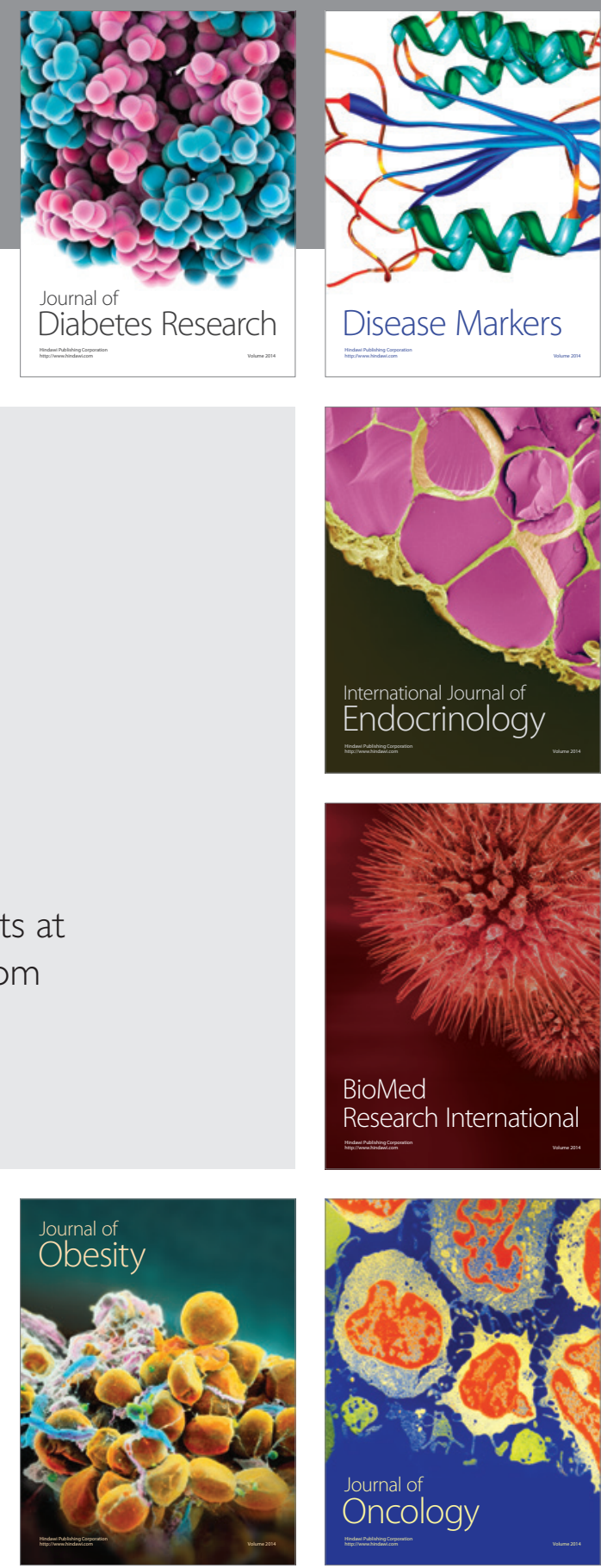

Disease Markers
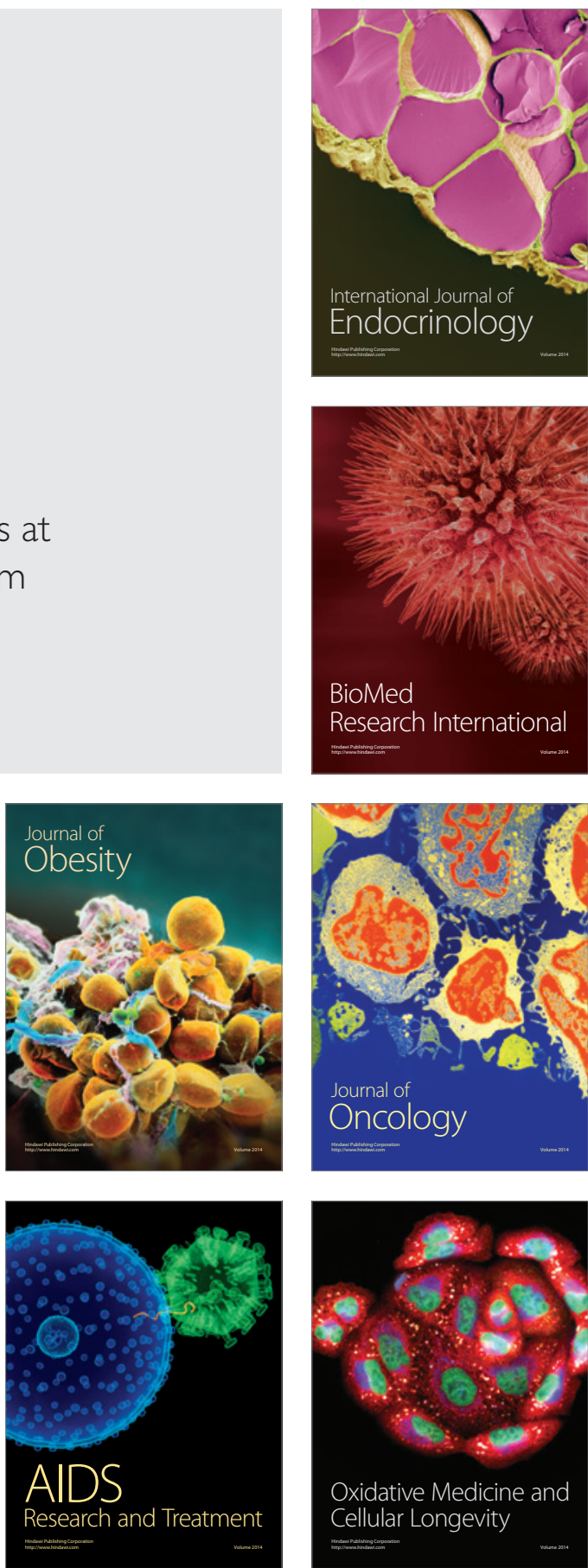